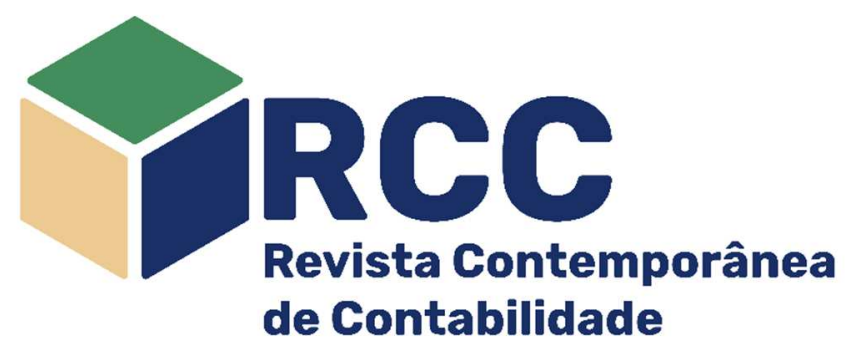

\title{
Plano de reorganização institucional anunciado pelo Banco do Brasil: um estudo empírico sobre a reação das ações do banco
}

\author{
Institutional reorganization plan announced by Banco do Brasil: an empirical study on reaction of the \\ bank stock
}

Plan de reorganización institucional anunciado por el Banco de Brasil: un estudio empírico sobre la reacción de las acciones del banco

\author{
Claudio Marcelo Edwards Barros* \\ Doutor em Contabilidade (UFPR) \\ Professor do Curso de Graduação e Pós-graduação em \\ Ciências Contábeis (UFPR), Curitiba/PR, Brasil \\ claudiomedwards@hotmail.com \\ http://orcid.org/0000-0001-7431-1627 (1)
}

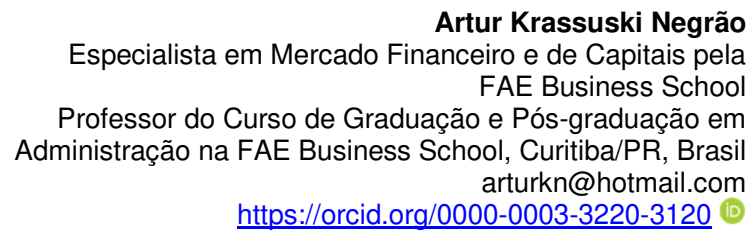

Artur Krassuski Negrão iro e de Capitais pela https://orcid.org/0000-0003-3220-3120
Sayuri Unoki de Azevedo Doutora em Contabilidade (USP) Professora do Curso de Graduação e Pós-graduação em Ciências Contábeis (UFPR), Curitiba/PR, Brasil sayuri.unoki@ufpr.br https://orcid.org/0000-0001-9676-9938 (i)

Jocelino Donizetti Teodoro
Mestre em Contabilidade (UFPR)
Socio-proprietário da empresa Arth Contábil,
Curitiba/PR, Brasil
jocelinodonizette@hotmail.com
https://orcid.org/0000-0003-1615-2140

Endereço do contato principal para correspondência* Av. Prefeito Lothário Meissner, 632 - Jardim Botânico, CEP: 80210-170 -Curitiba, PR, Brasil

\section{Resumo}

O presente estudo examinou o impacto do anúncio feito pelo Banco do Brasil do plano de Reorganização Institucional sobre o valor das ações da instituição financeira. Os ativos que compõe a amostra do estudo são ações e ADRs (American Deposit Receipts) do Banco do Brasil na B3 (Brasil, Bolsa, Balcão) e Nyse (Bolsa de Valores de Nova lorque). Adicionalmente, consideram-se as ações de instituições financeiras listados no Brasil (critério Peer Review), totalizando 15 ativos estudados. Foram conduzidos Estudo de Eventos para cada um dos ativos selecionados e adicionalmente foram realizados exames de robustez. Constatou-se a presença de Retornos Anormais positivos no dia de divulgação do evento. Este estudo mostrou que o anúncio das medidas tomadas pela instituição trouxe efeitos favoráveis à valoração das ações, conferindo surpresa positiva ao anúncio. Argumenta-se que, embora tais medidas já fossem aguardadas, os reflexos no preço das ações foram importantes o suficiente para que investidores observassem as decisões tomadas como adequadas para recondução da rentabilidade da instituição a níveis mais elevados no futuro.

Palavras-chave: Reorganização Institucional; Retornos Anormais; Valoração de Ações; Conteúdo Informacional; Estimadores Robustos.

\footnotetext{
Abstract

This study examined the impact of the announcement made by Banco do Brasil on the price of the bank's stocks. The assets that comprise the study sample are Banco do Brasil Stock Price on B3 (Brasil, Bolsa, Balcão) and ADRs (American Deposit Receipts) on Nyse (New York Security Exchange). Additionally, the shares of financial institutions listed in Brazil are considered according to the Peer Review criterion, totaling 15 assets studied. Event Studies were conducted for each of the selected assets and robustness tests were added. Positive Abnormal Returns were found on the day of the event. This study demonstrated that the
} 
announcement of the measures taken by the institution brought favorable effects to the valuation of the stocks, conducting a positive surprise to the announcement. It is argued that, although such measures were already awaited, the stock price reflexes were important enough for investors to observe the decisions taken as appropriate to bring the institution's profitability back to higher levels in the future.

Keywords: Institutional Reorganization; Abnormal returns; Stock Valuation; Informational Content; Robust Estimators.

\section{Resumen}

El presente estudio examinó el impacto del anuncio hecho por el Banco do Brasil del plan de Reorganización Institucional. Los activos que comprenden la muestra del estudio son el precio de las acciones de Banco do Brasil en B3 (Brasil, Bolsa, Balcão) y ADR (American Deposit Receipts) en Nyse (New York Security Exchange). Adicionalmente, se consideran las acciones de instituciones financieras listados en Brasil (criterio Peer Review). Se realizaron estudios de eventos para cada uno de los activos seleccionados y se realizaron exámenes de robustez. Se constató la presencia de Retornos anormales positivos en el día de divulgación del evento. Este estudio mostró que el anuncio de las medidas tomadas por el banco trajo efectos favorables a la valoración de las acciones, dando sorpresa positiva al anuncio. Se argumenta que, aunque tales medidas ya se esperaban, los reflejos en el precio de las acciones fueron lo suficientemente importan para que los inversores observasen las decisiones tomadas como adecuadas para la renovación de la rentabilidad de la institución a niveles más elevados en el futuro.

Palabras clave: Reorganización Institucional; Retornos anormales; Valoración de Acciones; Contenido Informacional; Estimadores robustos.

\section{Introdução}

Empresas brasileiras experimentaram intensa redução no ritmo de seus negócios nos anos de 2014, 2015 e 2016. Segundo o Instituto de Pesquisa Econômica Aplicada - IPEA (2016) foram onze trimestres de queda no Produto Interno Bruto (PIB). Medidas de redução da força de trabalho (Downsizings), suspensão temporária do trabalho (layoff), relaxamento de horas e redução de custos operacionais se tornaram recorrentes tendo em conta a necessidade das empresas de adequar sua estrutura de custos, principalmente força de trabalho, ao momento de retração da economia. Sociedades de Economia Mista e Empresas Públicas não passaram incólumes à necessidade de redimensionar sua força de trabalho e estrutura de gastos. Em 2016, como reação à necessidade de cortar custos para resguardar a rentabilidade de seus negócios, empresas estatais como Petrobrás, Banco do Brasil, Caixa Econômica, Correios, Conab, Banco da Amazônia, Dataprev, Infraero e Serpro anunciaram programas de demissão de funcionários cujo contingente poderia chegar a 34.651 pessoas (ALVARENGA, 2017).

Com expressiva difusão midiática, o Banco do Brasil anunciou no dia 20 de novembro de 2016 plano de redução de gastos denominado pela própria instituição financeira como "Reorganização Institucional do Banco do Brasil". Comunicado como fato relevante, a administração do banco tratou o anúncio como sendo o mais abrangente plano de reestruturação de gastos e operações já realizados. O plano estava concentrado em promover o fechamento de agências físicas de varejo, colocar em curso o programa de aposentadoria incentivada e implantar a revisão de processos internos com o propósito de expandir o atendimento digital do banco (BANCO DO BRASIL, 2016).

De acordo com Paulo Cicarelli, Diretor Presidente do Banco do Brasil em entrevista ao Jornal Correio Braziliense em 12/12/2016 (TEMÓTEO; NUNES, 2016), o Banco do Brasil tem folha de pagamento anual R\$ 3 bilhões mais elevada que de seus principais concorrentes (Itaú-Unibanco, Bradesco e Santander). Além disso, conforme mostra o relatório de desempenho dos Bancos brasileiros do Departamento Intersindical de Estatística e Estudos Socioeconômicos (DIEESE, 2017), em 2016 o Retorno sobre o Patrimônio Líquido ( $R O E$ ) do banco foi o menor dentre seus principais concorrentes (9,5\%) com queda de 46,63\% em $2016 \mathrm{com}$ relação a 2015. Segundo analistas do mercado acionário, a inciativa tomada pelo Banco do Brasil para enxugar sua estrutura de custos sinalizou o compromisso do banco em reconstituir seu $R O E$ no médio prazo e representa indicativo de evolução na valoração das ações do banco (RIZÉRIO, 2016). Comentaram ainda que, embora as medidas parecessem boas para o banco, poderiam ser prejudiciais para o BB Seguridade tendo em conta a dependência do negócio de seguros de agências bancárias. As medidas anunciadas pelo banco tiveram também repercussão internacional. De acordo com matéria divulgada no Wall Street Journal, a reestruturação anunciada representa esforço em expandir os canais digitais para aumentar a rentabilidade do banco (JELMAYER, 2016).

No ambiente de mercados acionários da América do Norte e Europa já existe extensa literatura desenvolvida com o propósito de compreender a reação do mercado do mercado de capitais em face de anúncios corporativos envolvendo downsizings (ABOWD; MILKOVICH; HANNON, 1990; MENTZER, 1996; BALLESTA; LIVNAT; SINHA, 1999; WAYHAN; WERNER, 2000; CHALOS; CHEN, 2002; KRISHNAN; PARK, 2002); layoffs (WORRELL; DAVIDSON; SHARMA, 1991; CHADWELL; FILBECK, 1994; URSEL; ARMSTRON-STASSEN, 1995; IQBAL; SHETTY, 1995; GUNDERSON; VERMA; VERMA, 1997; LEE, 1997; ELAYAN; SWALES; MARIS, 1998; FILBECK; WEBB, 2001; CHEN; VIKAS; RANJINI; WAYNE, 2001; HAHN; 
REYES, 2004; WERTHEIM; ROBINSON, 2004; HILLIER; MARSHALL; MCCOLGAN, 2007; BROOKMAN; CHANG; RENNIE, 2007; FARBER; HALLOCK, 2009; VELÁSQUEZ; KANNIAINEN; MÄKINEN; VALLI, 2016; KUNERT; SCHIERECK; WELKOBORSKY, 2017); e reduções de custos como um todo e fechamento de unidades (BLACKWELL; MARR; SPIVEY, 1990; GOMBOLA; TSETSEKO, 1992; LIN; ROZEFF, 1997). Especificamente no setor bancário o tema já é objeto de investigação desde meados dos anos de 1990. Considerando o crescimento de anúncios de layoffs, desenvolveram-se pesquisas com o fito de examinar o efeito da divulgação de planos de redução de despesas e layoffs sobre o mercado acionário de companhias do setor financeiro (MADURA; AKHIGBE; BARTUNEK, 1995; CHADWELL; MULLINEAUX, 1995; CAGLE; SEM; WEBB, 2004; CAGLE; SEN; PAWLUKIEWICZ, 2009).

No Brasil, o Banco do Brasil é o segundo maior banco com ativos de US\$430,54 bilhões, atrás somente de Itaú-Unibanco com US\$ 438 bilhões, tem 4972 agências de varejo espalhadas no Brasil, 63 milhões de clientes e 109.864 funcionários (BLOOMBERG, 2016). Em sendo um banco controlado pelo Governo, em caso de dificuldades financeiras, este pode fazer aportes financeiros via Secretaria do Tesouro Nacional do Brasil, hipótese essa que não foi aventada no plano de reestruturação anunciado pelo banco, mas que se revela temerária possibilidade de ocorrência, sobretudo pelo fato do banco ser um "braço" do Governo Federal na implementação de políticas públicas (SILVA, 2010). Além disso, o Banco do Brasil tem suas ações negociadas nos Estados Unidos e, portanto, ações e decisões corporativas que possam exercer influência sobre a valoração de seus ativos serão sempre submetidas também ao escrutínio de agentes internacionais, tais como investidores, bancos de investimento e da própria SEC (Security Exchance Commission).

Diante disso, tem-se que o banco necessita mostrar desempenho de maneira a atender aos anseios de um público diversificado colocando as recentes medidas tomadas no centro da avaliação daqueles que tem interesse no seu desempenho corporativo. Com base nesse preâmbulo, emerge a seguinte questão: qual o impacto no preço das ações do Banco do Brasil ao anúncio do conjunto de medidas de redução de gastos realizado em 21 de novembro de 2016? O artigo tem o objetivo de examinar o impacto gerado pelo anúncio feito pelo banco no valor das ações, o que inclui a ação negociada na $\mathrm{B}^{3}$ (Brasil, Bolsa, Balcão) e as ADRs (American Deposit Receipts) negociadas na Nyse (New York Security Exchange).

Considerando que na bolsa de valores brasileira são negociadas ações dos principais concorrentes do Banco do Brasil, decidiu-se expandir a análise de constatação de efeitos do anúncio a todos os bancos com ações listadas na bolsa. Essa inclusão se justifica pela preocupação em observar se a constatação de impacto positivo, negativo ou neutro reflete o específico apreçamento das ações do banco em decorrência do anúncio do plano restruturação do banco.

Esse estudo é importante porque examina a interpretação do mercado acionário sobre as medidas anunciadas pela maior empresa estatal brasileira, em meio à retração econômica mais longa já registrada no Brasil. Em linha diferente de estudos anteriores que priorizam o exame da percepção de trabalhadores sobre os processos de implantação de planos de demissão ou aposentadoria voluntária ou ainda modificações no funcionamento do mercado de trabalho no setor bancário a exemplo dos estudos de Segnini, (1999), Silva (2002) e Carrijo e Navarro (2009), este estudo contribui para literatura ao descrever parte importante da perspectiva externa ao banco por meio da reação do mercado secundário de ações ao anúncio realizado em 21 de novembro de 2016. Desse modo, almeja minuciar um panorama mais geral de reação às medidas anunciadas por parte de investidores, acionistas e demais agentes de mercado tais como analistas e outras instituições do sistema financeiro.

Deve-se ressaltar que esta pesquisa investiga a presença de conteúdo informacional relacionado ao anúncio de plano de reestruturação da maior instituição financeira estatal do Brasil e, para isso, ancora-se em literatura de ampla origem. Como já aludido na contextualização do objetivo da pesquisa, reestruturações podem abranger configurações de downsizings, layoffs e medidas de redução de custos e fechamento de unidades, estudos estes realizados em setores financeiros e não financeiros em diversos países. Essas medidas podem não ser implementadas abrangendo configurações isoladas, mas inseridas em um contexto de causas múltiplas em termos de revisão de estruturas organizacionais. Nessa direção, dada a pluralidade de abrangência do Plano de Reestruturação Institucional feito pelo Banco do Brasil, que envolveu não somente redução de contingente de mão de obra, mas também o redirecionamento de receita via canais digitais, o resgate de literatura não se limitou a tipos específicos de reestruturações e priorizou interpretar a reação de mercados acionários diante de anúncios de modificações estruturais potencialmente impactantes ao valor de mercado de corporações.

\section{Revisão de Literatura}

\subsection{Detalhamento do plano}

Divulgado como fato relevante em um domingo (20 de novembro de 2016), o plano denominado Reorganização Institucional do Banco do Brasil continha medidas corporativas com abrangência em 3 frentes de atuação: i) Redimensionamento da Estrutura Organizacional; ii) Plano de Aposentadoria Incentivada; e iii) Realocação de mão-de-obra e revisão de processos. 
Em relação ao Redimensionamento Organizacional, o banco se comprometia em fazer adequações, em todos os estados do Brasil, na quantidade de unidades de atendimento mantidas pelo banco. Em relação às agências anunciou redução de 781 unidades, o que equivale à $15,71 \%$ de toda a oferta de serviços do banco em agências de varejo. Ampliação de 245 para 500 agências e escritórios digitais, decisão que mostrou a intensão do banco em ampliar sua atuação digital. Em relação ao atendimento digital o banco também anunciou (1) o objetivo de ampliar a rede de clientes atendidos por unidades de atendimento digital de 1,3 milhão para 4 milhões, (2) a ampliação da rede clientes que utilizam aplicativos de smartphone (canal mobile) de 9,4 milhões para 15 milhões de usuários e (3) expansão da utilização da conta digital de 10 mil para 1,8 milhão de contas. Cargos de alta administração também foram alvos das medidas anunciadas. A instituição se comprometeu em reduzir 3 Diretorias Gerais, 28 Superintendências Regionais de varejo e 3 Superintendências dedicadas a atender o setor público (Governo). Além disso, o anúncio envolvia o encerramento de 2 centros de serviços compartilhados e 7 gerências regionais de controles internos.

O Plano de Aposentadoria Incentivada anunciado pelo Banco do Brasil tinha como público alvo o alcance de 18 mil funcionários e provavelmente foi a parte mais representativa do plano em termos de redução de despesas recorrentes. A Tabela 1 apresentada a seguir demonstra o valor de despesas com pessoal do Banco do Brasil e de seus principais concorrentes no Brasil.

Tabela 1 - Despesas com pessoal para os anos de 2013, 2014 e 2015

\begin{tabular}{|c|c|c|c|c|}
\hline $\begin{array}{l}\text { Instituição } \\
\text { Financeira }\end{array}$ & Ano & $\begin{array}{l}\text { Quantidade de } \\
\text { funcionários }\end{array}$ & $\begin{array}{l}\text { Despesa com Pessoal (em } \\
\text { bilhões de reais) }\end{array}$ & $\begin{array}{l}\text { Despesas Médias (em } \\
\text { bilhões de reais) }\end{array}$ \\
\hline \multirow{3}{*}{ Banco do Brasil } & 2013 & 113.199 & 18,818 & \multirow{3}{*}{19,670} \\
\hline & 2014 & 111.922 & 18,862 & \\
\hline & 2015 & 110.410 & 21,329 & \\
\hline \multirow{3}{*}{ Itaú Unibanco } & 2013 & 96.337 & 15,860 & \multirow{3}{*}{17,503} \\
\hline & 2014 & 94.436 & 17,071 & \\
\hline & 2015 & 91.748 & 19,573 & \\
\hline \multirow{3}{*}{ Bradesco } & 2013 & 101.937 & 12,354 & \multirow{3}{*}{13,360} \\
\hline & 2014 & 111.922 & 13,667 & \\
\hline & 2015 & 110.410 & 14,058 & \\
\hline \multirow{3}{*}{ Santander } & 2013 & 47.000 & 7,045 & \multirow{3}{*}{7,349} \\
\hline & 2014 & 47.506 & 7,203 & \\
\hline & 2015 & 47.916 & 7,798 & \\
\hline
\end{tabular}

Fonte: CVM. Demonstração do Resultado Consolidado de 31.12.2015. O ano de 2016 foi suprimido da Tabela porque ainda em 2016 foram apropriadas reduções de despesas de pessoal em função da aderência de parte de funcionários do Banco do Brasil ao Plano de Aposentadoria Incentivada.

Mostra-se na Tabela 1 que a média das despesas com pessoal do Banco do Brasil foi de $\mathrm{R} \$ 2,169$ bilhões mais elevada que a média das despesas do banco Itaú Unibanco no mesmo período. Especificamente no ano de 2013, a Tabela 1 mostra que as despesas com pessoal do Banco do Brasil foram maiores em $R \$$ 2,958 bilhões. Sobre a realocação da força de trabalho e revisão de processos, o banco informou que em decorrência da extinção de diretorias, superintendências e unidades de atendimento do banco, mais de 9.000 funcionários serão realocados seja na forma de ocupação de cargos semelhantes ou por meio de promoções. Adicionalmente, o banco afirma ter identificado oportunidades de ganho de eficiência na revisão de processos internos diretamente ligados ao atendimento de clientes e, portanto, potencializando redução de gastos nessa área. Deve-se observar que a divulgação do Plano de Reorganização Institucional não elencou medidas de retração de investimentos e, portanto, há motivos para acreditar que sua implementação não é motivada por cortes estruturais na instituição. Logo, pode-se defender que o Plano não alcançou a capacidade de geração de receita futura.

\subsection{Revisão de Literatura}

Um dos primeiros estudos direcionados a examinar reflexos de decisões corporativas de Downsizings foi realizado por Abowd, Milkovich e Hannon (1990) que, por meio da categorização de 5 tipos de anúncios (decisões de recursos Humanos em geral, remuneração, realocação de mão-de-obra, mudanças na staff gerencial e outras medidas), examinaram a valoração das ações das empresas anunciantes. Não encontraram padrões de valoração nas ações como resposta a anúncios realizados considerando as categorias como um todo. No entanto, ao se considerar anúncios de cortes permanentes no staff gerencial e realocações de mão-de-obra, evidenciaram a geração de retornos anormais positivos ao redor das datas de anúncio.

Considerando o intenso aumento de investimentos em tecnologia e massiva redução da força de trabalho ocorrida ao longo dos anos 90, Ballesta, Livnat e Sinha (1999) examinaram a ligação entre reestruturação organizacional e performance financeira de uma grande amostra de empresas ao redor do mundo. Os resultados obtidos indicaram que empresas que realizaram reduções específicas na força de trabalho independentes de mudanças no nível de investimentos (Capital Expenditures) apresentam valoração 
no mercado de ações relativamente forte, apesar de redução na rentabilidade. Realçam que é essencial examinar variáveis do ambiente macroeconômico para interpretar a reação do mercado de capitais quanto às decisões tomadas pela corporação.

Semelhante ao contexto explorado por Ballesta, Livnat e Sinha (1999), mas considerando exclusivamente o mercado norte-americano, Wayhan e Werner (2000) analisaram o impacto das reduções de mão de obra sobre o desempenho econômico financeiro das 250 maiores empresas norte-americanas. Constataram que a redução na força de trabalho levou a um aumento expressivo da capitalização de mercado, mas a um baixo crescimento das receitas no curto prazo. Defenderam que Downsizings podem ser bons como estratégia de reestruturação, pelo menos no curto prazo.

No Canadá, Mentzer (1996) investigou se a realização de Downsizings leva a aumentos de rentabilidade no futuro. Segundo o autor, a ausência de padrões consistentes que apontem para a melhoria do desempenho econômico-financeiro após as reduções de força de trabalho anunciadas sugere que a alta administração de empresas que anunciam Downsizings pensa estar "cortando gorduras" na estrutura de mão de obra, mas em parte significativa das vezes podem estar cortando o que o autor denominou de "musculatura da força de trabalho" e, portanto impedido a expansão dos negócios.

Chalos e Chen (2002) também estudaram os efeitos de estratégias corporativas de Downsizings em termos de reação do mercado acionário e desempenho e valoração corporativa pós-anúncio. Constataram que o mercado reage de forma seletiva a anúncios de Downsizings. Sobre a geração de retornos anormais ao redor das datas de anúncios de medidas de Downsizings, não foram constados efeitos significativos. No que tange a anúncios ligados a redução de custos com impacto direto sobre o custo dos produtos vendidos (CPV) constataram também não haver reação alguma. Entretanto, diferente de estudos prévios anúncios, reação positiva foi observada para circunstâncias relacionadas à layoffs associados à reorientação de receitas. Nessa linha de investigação, Nixon, Hitt, Lee e Jeong (2004) verificaram que anúncios de medidas de Downsizings produzem retornos de mercado negativos e, portanto, contrariam parte dos achados de Chalos e Chen (2002).

Embora não seja possível negar que layoff seja espécie de Downsizing nas corporações tendo o fato de que ambos lidam como reduções ou com imposição de limitação a força de trabalho da firma, há extensa literatura em finanças que particulariza o exame do impacto do anúncio de layoffs sobre os preços de ações. Semelhante aos estudos que abrangem o efeito de ações de Downsizing há também resultados de impactos negativos ou até mesmo positivos e mistos sobre a valoração de ações quando o tema central é a divulgação de layoffs. Possivelmente o primeiro trabalho empírico sobre o tema foi desenvolvido por Worrell, Davidson III e Sharma (1991) ao examinar a reação no preço das ações de anúncios de layoffs temporários e definitivos. Afirmam que a reação de investidores é negativa, cuja intensidade é piorada quando o layoff ocorre por dificuldades financeiras (Financial Distress) e sugerem que essa reação é interpretada como uma sinalização de que problemas mais profundos tem alta probabilidade de ocorrer em futuro próximo. Esses autores são proponentes da Hipótese de Dificuldades Financeiras para layoffs (Financial Distress) que se baseia na premissa de que o sinal enviado por meio de anúncios de layoffts tende a reiterar que a situação financeira presente da empresa é ruim. Essa hipótese sustenta que a reação no preço das ações será negativa.

Ursel e Armstrong-Stassen (1995) investigou a reação no preço das ações de empresas canadenses quanto aos anúncios de layoffs. Os resultados indicaram reação negativa no preço das ações e quando os anúncios são realizados em série, os primeiros comunicados são negativamente mais intensos que os demais. Semelhante a Mentzer (1996) ao estudar o ambiente de mercado de capitais do Canadá, Gunderson, Verma e Verma (1997) confirmaram os resultados de Ursel e Armstrong-Stassen (1995) e adicionam a informação de que a reação anormal dos retornos diários no mercado de ações ocorreu no dia do anúncio. Resultados na mesma direção foram observados por Lee (1997) que comparou a intensidade de reação a anúncios de layoffs nos EUA e no Japão, tendo constatado reação negativa, embora menos intensa no mercado acionário japonês. Elayan et al. (1998) que, além de também ter observado reações negativas dos anúncios, defendem que companhias envolvidas nesses anúncios têm menos oportunidades de investimento no futuro. Outros estudos que evidenciam efeitos negativos de anúncios de layoffs foram constatados por Filbeck e Webb (2001), Chen et al. (2001), Hahn e Reyes (2004), Hillier, Marshall e McColan (2007), Farber e Hallock (2009), Velásquez et al. (2016) e Kunert, Schiereck e Welkoborsky (2017).

Há pesquisadores que apresentaram indícios de reação positiva ou mista sobre o preço de ações de empresas que anunciaram layoffs. Iqbal e Shetty (1995) encontraram retornos anormais negativos acima de dois dias após o anúncio, o que fortalece os achados de Worrell, Davidson III e Sharma (1991). No entanto, aqueles autores promoveram a divisão da amostra com o objetivo de examinar se os resultados eram diferentes considerando corporações financeiramente saudáveis e não saudáveis e efetivamente encontraram diferenças. Mostram que empresas financeiramente não saudáveis apresentaram reações positivamente mais intensas se comparadas às reações de companhias financeiramente saudáveis. Ressaltam ainda que layoffs acompanhados de medidas de cortes de custos e infraestrutura apresentam impacto positivo no preço das ações. Embora defendam que parte dos resultados enfraqueçam a relação encontrada por Worrell, Davidson III e Sharma (1991), assinalam que diferenças no percurso metodológico para tratamento estatístico dos dados e diferenças no tamanho da amostra podem ter exercido influência na geração de resultados diferentes. Iqbal e Shetty (1995) são proponentes da Hipótese de Benefícios Potenciais 
para layoffs (Potential Benefit Hypothesis) que tem como premissa o fato de que layoffs ocorrem porque a empresa busca cortar custos para melhorar o lucro. Empresas se envolvem em layoffs porque buscam benefícios futuros, tentam evitar a falência e, portanto, o resultado do anúncio seria a apreciação das ações da corporação.

Por meio de expressiva amostra de 604 anúncios de layoffs em empresas norte-americanas, Wertheim e Robinson (2004) analisaram a reação no preço das ações e conciliaram resultados que fortaleceram tanto a Hipótese de Dificuldades Financeiras quanto a Hipótese de Benefícios Potenciais. Para empresas que apresentaram reação negativa no preço das ações na data do anúncio do layoff, quando maior o tamanho do layoff (quantidade de pessoas afetadas), maior a intensidade negativa da reação. Também para essas companhias, quão menor o tamanho da companhia, maior a intensidade negativa da reação. Esses resultados confirmam a Hipótese de Dificuldades Financeiras. Por outro lado, empresas que obtiveram reação positiva no preço das ações, quão maior o tamanho do layoff, maior a intensidade positiva da reação. Também para essas empresas, quão menor o tamanho da companhia, maior a intensidade positiva da reação. Tais resultados são coerentes com a Hipótese de Benefícios Potenciais.

Reações positivas no preço das ações foram também observadas por Brookman, Chang e Rennie (2007). Em estudo empírico que evidenciou que CEOs (Chief Executive Officers) de companhias anunciantes de layoffs receberam, em média, $22,8 \%$ a mais de remuneração (no ano seguinte ao anúncio do Layoff) em relação aos CEOs não envolvidos nessa circunstância, constatou-se que os anúncios de layoffs foram seguidos de reações no preço das ações positivas e expressivas.

Estudos sobre a revisão da magnitude da força de trabalho também já foram desenvolvidos no ambiente próprio de instituições financeiras. Chadwell e Filbeck (1994) investigaram a reação de anúncios de layoffs em companhias reguladas (bancos) e não reguladas. Demonstraram que empresas reguladas experimentaram valoração expressiva ante a reação nula de empresas não reguladas. Além disso, sempre que os anúncios envolviam reestruturações organizacionais, estes eram seguidos de reações mais favoráveis ao preço das ações.

Tendo em conta que alterações na estrutura de empregos não alteram a estrutura de dívida e nem dos ativos, Madura, Akhigbe e Bartunek (1995) argumentam que anúncios de layoffs podem sinalizar modificações profundas na eficiência ou presença de problemas financeiras na instituição financeira que anuncia layoffs. Ao investigar o efeito geral de anúncios de layoffs na indústria bancária, mostraram que a reação é negativa para os bancos que anunciaram os layoffs, mas é positiva para os bancos rivais quando os lucros estão altos. Defendem que a propagação de resultados positivos em bancos competidores revela probabilidade dessas instituições em ganhar participação de mercado em momentos seguintes.

Ao contrário de Madura, Akhigbe e Bartunek (1995), Chadwell e Mullineaux (1995) notaram reação positiva no preço das ações de bancos (holdings) anunciantes de layoffs. Defendem que esses retornos favoráveis são proporcionais a magnitude do layoff anunciado, ou seja, quão maior o tamanho do layoff , mais intensa a apreciação das ações. Em linha com esses achados, Cagle, Sen e Pawlukiewicz (2009) investigaram o reflexo dos anúncios de layoffs em toda a indústria financeira, a qual inclui empresas bancárias e não bancárias. Evidenciaram que bancos experimentaram retornos anormais positivos e outras empresas do setor financeiro, mas não bancárias, apresentaram efeitos nulos. Os resultados mais favoráveis aos bancos se mantiveram como positivos mesmo após o controle de efeitos como tamanho da empresa, tamanho do layoff, motivo para o layoff e estrutura de Governança Corporativa.

Como pôde ser mostrado nesta revisão de literatura, parte significativa de estudos ligados ao tema estão ancorados na ideia de buscar revelações a partir do apreçamento de ações de companhias listadas em bolsa de valores. Logo, a obtenção de estabilidade e acurácia na geração de retornos anormais é um ponto de importância central nos achados dessas pesquisas. Nesse sentido, Sorokina, Booth e Thornton (2013) argumentam que séries de retornos diários - inputs de dados essenciais para a condução de estudos de eventos - tendem a ocultar observações expressivamente desviantes da média, denominados outliers. Por sua vez, como as estimações dos parâmetros alfa (intercepto) e beta (inclinação) ocorrem por meio de mínimos quadrados ordinários (MQO), as quais se baseiam em média, a presença de outliers pode gerar coeficientes capazes de levar o pesquisador a conclusões distorcidas sobre um ou mais eventos estudados. Em investigação de natureza predominantemente metodológica, os autores defendem que estimadores robustos a outliers, a exemplo do MM-Estimator, especificamente esse disponível no aplicativo de estatística e econometria Eviews, podem ser mais precisos em capturar retornos anormais na janela de eventos, em comparação aos retornos anormais calculados por MQO. Ressaltam ainda que é temerário excluir dados que possam ser considerados outliers, tendo em vista de que neles pode existir conteúdo informacional útil para o (s) evento (s) em estudo. Por fim, deve-se ressaltar que em nenhum momento do trabalho os autores afirmam que o uso de estimadores robustos é melhor em todas as circunstâncias, mas sim reiteram que pesquisadores não devem ignorar a presença de outliers em suas investigações.

\subsection{Hipótese de Pesquisa}

Ações de Downsizing estão geralmente ligadas a reestruturações organizacionais, as quais tendem a envolver mudanças profundas na condução dos negócios e na configuração das operações da firma. Quase 
sempre essas mudanças se refletem em alterações na estrutura de custos e despesas operacionais. A partir de decisões dessa natureza, as corporações buscam melhorar resultados futuros e ampliar sua eficiência (CHALOS; CHEN, 2002). Entretanto, apesar de anúncios de medidas de restruturação mostrarem esse intento, elas podem prejudicar a própria eficiência e ainda revelar problemas financeiros da empresa anunciante (MADURA, AKHIGBE e BARTUNEK, 1995), o que parece não ser o caso do Banco do Brasil. Mesmo a despeito da retração da atividade econômica desde 2015, que afetou a rentabilidade de toda a indústria financeira, o banco manteve expressivo lucro líquido. Foi observada atuação pró-cíclica por parte do banco que seguiu a trajetória de decisões de bancos concorrentes em reduzir a oferta de crédito, aumentar da taxa de juros e expandir do spread bancário (DIEESE, 2017).

Neste sentido, as medidas do plano de Reorganização Institucional carreadas pelo banco não envolveram a retração de investimentos ou ainda o delineamento de cenários que mostrassem a propensão do banco em acessar fundos do Tesouro Nacional do Brasil, o que em conjunto, mostra que os anúncios realizados pelo banco não estão ligados a dificuldades financeiras enfrentadas pela instituição.

Ballesta, Livnat e Sinha (1999) defendem que medidas estruturantes envolvendo ajustes da força de trabalho exercem influência positiva no aumento da capitalização das empresas anunciantes. Chalos e Chen (2002) defendem que ajustes na força de trabalho acompanhados de medidas de redirecionamento de receitas geram retornos de mercado positivos. Além disso, medidas estruturantes na força de trabalho direcionadas a incrementar de resultados (CHADWELL; FILBECK, 1994; CHADWELL; MILLINEAUX, 1995; CAGLE, SEN; PAWLUKIEWICZ, 2009) estariam propensas a ocasionar reações positivas no preço das ações. Com base nisso, esse trabalho apresenta a seguinte Hipótese de Pesquisa: $O$ anúncio do plano de Reorganização Institucional do Banco do Brasil conduziu conteúdo informacional ao mercado acionário produzindo retornos anormais positivos na ação da instituição negociada na $B^{3}$ (Brasil, Bolsa, Balcão) e na Nyse (Bolsa de Valores de Nova lorque).

\section{Metodologia}

O objetivo do presente estudo é examinar o impacto do anúncio feito pelo Banco do Brasil do conjunto de medidas de redução de despesas sobre o preço das ações do banco e ADRs. Em linha com estudos prévios que investigaram reflexos sobre o preço das ações de medidas ligadas a Downsizings, layoffs e outras decisões de reestruturação corporativa, utiliza-se nessa pesquisa a metodologia econométrica do Estudo de Eventos (ABOWD, MILKOVICH; HANNON, 1990; WORRELL; DAVIDSON III; SHARMA, 1991; CHADWELL; FILBECK, 1994; CHADWELL; MULLINEAUX, 1995; CHALOS; CHEN, 2002; CAGLE; SEN; PAWLUKIEWICZ, 2009). As etapas apresentadas a seguir buscam detalhar os métodos empregados com vistas a principalmente garantir a replicabilidade do percurso metodológico do estudo.

\subsection{Definição do evento e da janela de eventos}

O evento de interesse desta pesquisa é o anúncio do plano de Reorganização Institucional do Banco do Brasil ocorrido no dia 20 de novembro de 2016. Tendo em conta que este dia foi um domingo, o dia potencialmente capaz de capturar os reflexos da notícia foi o primeiro dia útil seguinte ao anúncio, ou seja, segunda-feira 21 de novembro de 2016.

\subsection{Critérios para seleção de ativos}

Os ativos utilizados no estudo são as ações (também denominadas de tickers) ordinárias (ON) do Banco do Brasil negociadas na $\mathrm{B}^{3}$ (ticker BBSA) e ADRs (ticker BDORY) negociada nos Estados Unidos em Mercado de Balcão. Levando em consideração que este estudo busca investigar se o efeito dos anúncios é algo particular ocorrido nas ações do Banco do Brasil, não se poderia ignorar a possibilidade de observância de efeitos em outros bancos brasileiros. Uma possível reação significativa poderia se repetir em todo o segmento financeiro, o que enfraqueceria a hipótese de uma reação específica do Banco do Brasil em decorrência do anúncio do plano. Por isso, a partir da função Peer Analysis dos terminais Bloomberg® e Thomson Reuters Eikon ${ }^{\circledR}$ foram incluídos todos os pares do Banco do Brasil que apresentassem cotação diária para o intervalo da Janela de eventos, quais sejam: Bradesco (tickers BBDC ON e PN), Itau Unibanco (tickers ITUB ON e PN), Banco do Rio Grande do Sul (PN), Banco ABC (ticker ABC PN), Banco Pan (ticker BPAN PN), Banco Pine (ticker Pine PN), BTG Pactual (ticker BBTG), Santander (ticker SANB ON e PN).

Considerando que a empresa BB seguridade poderia ser afetada pelo conjunto de medidas anunciadas pelo Banco do Brasil, sobretudo aquelas ligadas ao fechamento de agências físicas, as quais representam canais potencialmente úteis para comercialização de seguros do BB seguridade, decidiu-se incluir na análise também os tickers BBSE ON negociado no Brasil e BBSEY negociado nos Estados Unidos. Considerando que são 15 ações selecionadas para análise foram conduzidos 15 estudos de eventos.

\subsection{Janela de estimação e determinação de retornos observados, esperados e anormais}

No presente trabalho a Janela de estimação se estende ao período de 01 de janeiro de 2010 a 10 de 
novembro de 2016, por meio da determinação dos retornos observados em frequência diária. Estes retornos são o retorno diário das ações selecionadas, identificado por $\left(R_{i}\right)$ na forma de capitalização continua e retorno diário de mercado representado pelo lbovespa $\left(R_{m t}\right)$ ou S\&P 500 também em capitalização continua, ambos determinados conforme a seguir:

$$
\begin{aligned}
R_{i} & =L N\left(P_{t} / P_{t-1}\right) \\
R_{m t} & =L N\left(C_{t} / C_{t-1}\right)
\end{aligned}
$$

O preço da ação no momento $t$ é identificado por $P_{t}$; $O$ preço da ação no momento $t$ - 1 é identificado por $P_{t-1}$. A cotação da Carteira de Mercado no momento $t$ (lbovespa) é identificada por $C_{t}$. A cotação da Carteira de Mercado no momento $t-1$ (Ibovespa) é identificada por $C_{t-1}$. Ln representa a forma logarítmica utilizada para determinação dos retornos diários em capitalização contínua. Os preços $\left(P_{t}\right.$ e $\left.P_{t-1}\right)$ utilizados são os preços de fechamento os quais estão ajustados a splits, inplits e remuneração de dividendos.

Os retornos diários observados na ação $\left(R_{i}\right)$ e os retornos diários observados no Mercado $\left(R_{m t}\right)$ configuram-se como duas variáveis que representam a Janela de Estimação em si. A partir dessas variáveis foram estimados os parâmetros necessários para determinação dos retornos diários esperados e retornos diários anormais. Esta estimação ocorreu por meio da aplicação de Mínimos Quadrados Ordinários (MQO) na forma de uma regressão linear simples comumente denominada de Modelo de Mercado, a qual tem a seguinte especificação:

$$
R_{i}=\alpha_{i}+\beta_{i} R_{m t}+\varepsilon_{i}
$$

Os retornos diários esperados são os retornos que seriam produzidos pelo ativo em questão a partir dos parâmetros $\alpha$ e $\beta$ estimados e também a partir dos retornos diários de mercado observados dentro da Janela de Eventos. Os retornos esperados são operacionalizados conforme a equação a seguir:

$$
E\left(R_{i} \mid R_{m}\right)=\alpha_{i}+\beta_{i} R_{m t}
$$

Os retornos diários anormais representam a diferença entre os retornos diários observados dados por $R_{i}$ e os retornos diários esperados determinados por $E\left(R_{i} \mid R_{m}\right)$. Assim, operacionalizaram-se os retornos diários anormais $\left(A R_{i}\right)$ conforme a equação a seguir:

$$
A R_{i}=\operatorname{Ln}\left(P_{t} / P_{t-1}\right)-E\left(R_{i} \mid R_{m}\right)
$$

Ao se substituir a Equação 4 na Equação 5, obtém-se a equação 6 restando evidenciado que o retorno diário anormal $\left(A R_{i}\right)$ representa um excedente positivo ou negativo estimado dentro da janela de eventos. Caso esse excedente seja expressivo, ter-se-á um evento significativo ao nível de $10 \%, 5 \%$ ou $1 \%$, respectivamente. Tanto o retorno diário anormal quanto o retorno diário esperado são calculados somente para o intervalo de 11 dias, o qual representa a Janela de Eventos.

$$
A R_{i}=\operatorname{Ln}\left(P_{t} / P_{t-1}\right)-\left(\alpha_{i}+\beta_{i} R_{m t}\right)
$$

\subsection{Procedimentos de estimação de retornos}

Os dados apresentados na seção de Análise de Dados se baseiam nas inferências estatísticas dos retornos anormais $\left(A R_{i}\right)$ e retornos anormais acumulados $\left(C A R_{i}\right)$. Os retornos anormais são determinados por meio da diferença entre o retorno observado, como já apresentado. Retornos anormais acumulados são determinados pela soma dos retornos anormais diários contidos na Janela de Eventos por meio da seguinte identidade:

$$
\operatorname{CAR}_{i(t 1, t 2)}=\sum_{t=t_{1}}^{t_{2}} A R_{i}
$$

\subsection{Procedimentos para teste de hipóteses}

Nesta subseção é apresentado o percurso metodológico utilizado para realização dos Testes Hipóteses relacionados aos retornos diários anormais $\left(A R_{i}\right)$ e aos retornos anormais acumulados $\left(C A R_{i}\right)$. O objeto do teste de hipóteses na condução de Estudo de Eventos é a realização de inferências que permitirão a sustentação ou refutação da hipótes de pesquisa de que o anúncio do plano de Reestruturação Institucional do Banco do Brasil conduziu conteúdo informacional ao mercado acionário. Considerando que o arranjo teórico desenvolvido para definição da hipótese de pesquisa supõe que o efeito fora positivo, trata-se, portanto de Testes de Hipótese unilaterais (ou unicaudais) à direita. Assim, tem-se como hipóteses nulas e alternativas para $A R_{i}$ e $C A R_{i}$, as seguintes identidades:

Hipótese nula $\left(\mathrm{H}_{0}\right): A R_{i} \leq 0$

Hipótese alternativa $\left(\mathrm{H}_{1}\right): A R_{i}>0$

Hipótese nula $\left(\mathrm{H}_{0}\right): C A R_{i} \leq 0$

Hipótese alternativa $\left(\mathrm{H}_{1}\right): C A R_{i}>0$ 
Os Testes de Hipóteses para retornos anormais são operacionalizados por meio da comparação entre um valor critico $t$ (distribuição $t$ de student) e um valor $t$ calculado. Os valores críticos, considerando Testes de Hipóteses unicaudais, são 1,28, 1,64 e 2,33 para 10\%, 5\% e 1\% de significância estatística, respectivamente. O cálculo do valor $t$ para os retornos anormais dá-se por meio da razão entre o retorno anormal de cada um dos dias da Janela de Eventos e o erro-padrão da regressão (BENNINGA, 2008). Desse modo, valores calculados de $t$ que estiverem abaixo de $+1,28,+1,64$ e $+2,33$ não permitirão a rejeição da Hipótese nula $\left(\mathrm{H}_{0}\right)$ de que os retornos anormais (ou retornos anormais acumulados) são menores ou iguais à zero. Do contrário, valores calculados de $t$ acima de $+1,28,+1,64$ e $+2,33$ permitirão a rejeição da Hipótese Nula ao nível de $10 \%, 5 \%$ e 1\%, respectivamente. Isso significa que a hipótese desenvolvida na seção 2 desse estudo só poderá ser confirmada para retornos anormais associados a testes $t$ positivos e significativos no dia 21 de novembro de 2016.

\subsection{Tratamento de Outliers}

Wooldridge (2015) argumenta que estimações feitas por MQO são sensíveis à presença de outliers, o que se mostrou circunstância típica para os dados do presente estudo. Isso ficou evidente pelo fato de todas as séries temporais que serviram de Janela de Estimação para determinação dos parâmetros obrigatórios para determinação dos retornos anormais apresentarem retornos diários caracterizados como outliers. Essa situação foi constatada ao se aplicar a análise de distância de Mahalanobis para detecção de indícios de outliers para cada linha das séries de tempo usadas como Janelas de Estimação em todas as regressões. Diante da presença de outliers, foram realizadas estimações adicionais para os retornos anormais utilizandose estimação robusta para os parâmetros $\alpha$ e $\beta$ denominadas de LAD (Least Absolute Deviation - Desvios Mínimos Absolutos) e MM-Estimator. O objetivo dessa aplicação foi examinar o quão resiliente são os retornos anormais calculados a depender do estimador utilizado. A utilização de estimadores robustos à presença de informações expressivamente desviantes ou pontos de alavancagem dos dados na condução de Estudos de Eventos em finanças tem sido objeto de investigação e representa ponto crítico que não pode ser ignorado (SOROKINA; BOOTH; THORNTON, 2013).

\section{Análise e Discussão dos Resultados}

Apresentada a seguir, a Tabela 2 tem o objetivo de demonstrar as estimações de retornos anormais $\left(A R_{i}\right)$ para todos os dias que compõem a Janela de Eventos da pesquisa. Mostra-se na Tabela 2 que somente os ativos do Banco do Brasil (BBAS e BDORY) apresentaram Retornos Anormais $\left(A R_{i}\right)$ positivos e relevantes com 5,24\% e 7,69\%. Esses retornos estão associados a testes $t$ de 2,89 e 2,76 e, portanto, acima do valor crítico 2,33. Logo, pode-se afirmar que tanto a ação do Banco do Brasil negociada na $B^{3}$ quanto o ADR negociado nos EUA absorveram positivamente os efeitos do anúncio divulgado pelo banco sobre seu plano de reorganização. Nessa direção, pode-se rejeitar a Hipótese Nula de que tanto os Retornos Anormais $\left(A R_{i}\right)$ da ação quando do ADR são menores ou iguais a zero. Por conseguinte, esses resultados sustentam a hipótese de que o anúncio do plano de Reorganização Institucional do Banco do Brasil conduziu conteúdo informacional ao mercado acionário produzindo retornos anormais positivos na ação da instituição negociada na B ${ }^{3}$ (Brasil, Bolsa, Balcão).

Dado os resultados obtidos para os retornos anormais para o ativo BDORY, pode-se afirmar também que o anúncio do plano de Reorganização Institucional do Banco do Brasil conduziu conteúdo informacional ao mercado acionário produzindo retornos anormais positivos no ADR da instituição negociada em Mercado de Balcão nos Estados Unidos. Em relação aos estudos prévios que examinaram o reflexo de anúncios de decisões corporativas ligadas a revisão da força de trabalho e gastos operacionais, os resultados ora apresentados estão em linha com estudos no segmento financeiro que evidenciam a propagação de efeitos positivos sobre os ativos da empresa anunciante. Assemelham-se aos achados de Chadwell e Filbeck (1994) porque as evidências ora mostradas corroboram a ideia de que anúncios de reestruturações organizacionais são seguidos de reações favoráveis na direção do incremento do valor de mercado das firmas anunciantes.

As constatações dessa investigação também mostram similaridade às depurações feitas por Chadwell e Mullineaux (1995) e Cagle, Sen e Pawlukiewicz (2009) porque sustentam que o mercado secundário interpreta com confiança o enxugamento sobretudo de mão de obra em estruturas organizacionais que já poderiam estar sendo avaliadas como sobrecarregadas. Em sentido oposto, esses achados contrariam os resultados de Madura, Akhigbe e Bartunek (1995) que evidenciam reações negativas no mercado de ações para anúncios assemelhados. Nesse ponto especificamente pode estar um fato proveitoso para a compreensão da reação anormal positiva observada na Tabela 2 nos ativos do Banco do Brasil que é justamente o fato dos anúncios da instituição não terem envolvido possíveis cortes ligados a planos de investimentos e, de forma pragmática, o mercado de ações pode ter entendido que os cortes realizados não afetariam sua capacidade de crescer. Finalmente, não haveria motivos para acreditar na deterioração em sua capacidade de geração de lucro e, portanto, no acometimento do trajeto de recomposição de sua rentabilidade futura. 
Tabela 2 - Resultados dos Retornos Anormais $\left(A R_{i}\right)$ calculados para Janela de eventos para 5 dias anteriores e 5 dias posteriores ao anúncio do plano de Reestruturação Institucional pelo Banco do Brasil

\begin{tabular}{|c|c|c|c|c|c|c|c|c|c|c|c|c|}
\hline Ação/Seq. & $\begin{array}{l}5 \text { dias } \\
\text { antes }\end{array}$ & $\begin{array}{l}4 \text { dias } \\
\text { antes }\end{array}$ & $\begin{array}{l}3 \text { dias } \\
\text { antes }\end{array}$ & $\begin{array}{l}2 \text { dias } \\
\text { antes }\end{array}$ & 1 dia antes & Data Zero & $\begin{array}{c}1 \text { dia } \\
\text { depois }\end{array}$ & 2 dias dep. & 3 dias dep. & 4 dias dep. & 5 dias dep. & $\begin{array}{c}\text { Erro- } \\
\text { padrão }\end{array}$ \\
\hline BBDC4 (1) & $3,78 \% \%^{\star \star \star}$ & $-0,17 \%$ & $-0,52 \%$ & $-1,43 \%$ & $1,35 \%$ & $-1,44 \%$ & $-0,91 \%$ & $0,36 \%$ & $0,07 \%$ & $0,16 \%$ & $-1,05 \%$ & $1,16 \%$ \\
\hline BBDC3 (2) & $0,07 \%$ & $-1,16 \%$ & $0,16 \%$ & $-0,10 \%$ & $1,21 \%$ & $-1,31 \%$ & $0,37 \%$ & $0,57 \%$ & $-0,21 \%$ & $-0,03 \%$ & $-1,20 \%$ & $1,24 \%$ \\
\hline ITUB4 (3) & $2,29 \%$ ** & $-1,49 \%$ * & 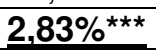 & $-1,29 \%$ & $0,57 \%$ & $-1,18 \%$ & $-1,23 \%$ & $-1,00 \%$ & $-0,04 \%$ & $-1,00 \%$ & $-0,17 \%$ & $1,13 \%$ \\
\hline ITUB3 (4) & $1,43 \%$ & $-2,04 \%^{*}$ & $2,53 \%$ ** & $-1,20 \%$ & $0,35 \%$ & $-0,15 \%$ & $-1,27 \%$ & $-0,40 \%$ & $-0,48 \%$ & $-0,47 \%$ & $-2,50 \% \%^{\star \star}$ & $1,26 \%$ \\
\hline ABCB4 (5) & $-1,48 \%$ & $0,26 \%$ & $0,94 \%$ & $-1,88 \%$ & $0,90 \%$ & $0,26 \%$ & $-0,74 \%$ & $0,39 \%$ & $3,52 \%$ ** & $-0,43 \%$ & $-2,16 \%$ & $1,89 \%$ \\
\hline BPAN4 (6) & $1,70 \%$ & $-0,26 \%$ & $-0,03 \%$ & $0,89 \%$ & $-0,76 \%$ & $-0,03 \%$ & $-2,02 \%$ & $-0,64 \%$ & $1,30 \%$ & $-2,23 \%$ & $-3,14 \%$ & $2,51 \%$ \\
\hline PINE4 (7) & $-0,73 \%$ & $0,75 \%$ & $-0,13 \%$ & $1,62 \%$ & $-1,30 \%$ & $-0,38 \%$ & $-1,22 \%$ & $1,74 \%$ & $0,29 \%$ & $1,46 \%$ & $1,13 \%$ & $1,88 \%$ \\
\hline BBTG11 (8) & $3,66 \%$ ** & $1,15 \%$ & $1,34 \%$ & $-2,41 \%$ & $3,16 \%{ }^{*}$ & $2,32 \%$ & $-2,23 \%$ & $0,01 \%$ & $-0,26 \%$ & $-2,64 \%{ }^{*}$ & $-1,31 \%$ & $2,04 \%$ \\
\hline BRSR6 (9) & $1,34 \%$ & $0,48 \%$ & $2,22 \%$ & $-2,03 \%$ & $-3,40 \%^{*}$ & $1,98 \%$ & $0,45 \%$ & $2,15 \%$ & $-1,19 \%$ & $-2,05 \%$ & $-0,68 \%$ & $2,28 \%$ \\
\hline BBAS (10) & $-3,03 \% \%^{\star \star}$ & $1,72 \%$ & $3,96 \%$ ** & $0,16 \%$ & $2,47 \%^{*}$ & $5,24 \%$ *** & $-0,55 \%$ & $-0,55 \%$ & $-1,54 \%$ & $-0,57 \%$ & $1,87 \%$ & $1,81 \%$ \\
\hline $\operatorname{BDORY}(11)$ & $1,16 \%$ & $3,40 \%$ & $2,33 \%$ & $-4,09 \%{ }^{*}$ & $4,25 \%$ * & $7,69 \%$ *** & $1,59 \%$ & $-2,37 \%$ & $-4,07 \%$ * & $5,17 \%$ ** & $-3,22 \%$ & $2,79 \%$ \\
\hline BBSE (12) & $0,70 \%$ & $-0,76 \%$ & $1,74 \%$ & $-0,12 \%$ & $0,83 \%$ & $-1,93 \%$ & $-0,56 \%$ & $-1,57 \%$ & $-1,18 \%$ & $-1,16 \%$ & $0,71 \%$ & $1,70 \%$ \\
\hline BBSEY (13) & $-2,35 \%$ & $2,65 \%$ & $0,59 \%$ & $-3,25 \%$ & $4,14 \%$ * & $-0,84 \%$ & $0,49 \%$ & $-2,86 \%$ & $-4,92 \%$ ** & $4,71 \%$ ** & $-2,53 \%$ & $2,65 \%$ \\
\hline SANB3 (14) & $-2,96 \%$ & $6,35 \%$ * & $6,77 \%$ * & $-4,12 \%$ & $6,91 \%{ }^{*}$ & $2,99 \%$ & $-1,37 \%$ & $-6,45 \%{ }^{*}$ & $1,26 \%$ & $1,53 \%$ & $0,04 \%$ & $4,88 \%$ \\
\hline SANB4 (15) & $3,83 \%$ & $-7,57 \%$ * & $0,13 \%$ & $0,13 \%$ & $8,30 \% \%^{\star *}$ & $-3,32 \%$ & $2,04 \%$ & $1,61 \%$ & $-0,15 \%$ & $0,54 \%$ & $-2,80 \%$ & $4,95 \%$ \\
\hline
\end{tabular}

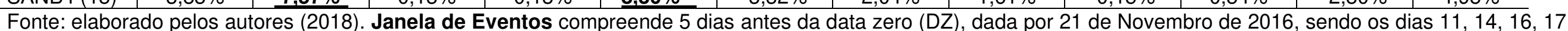

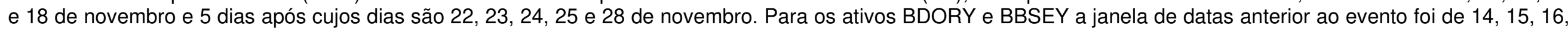

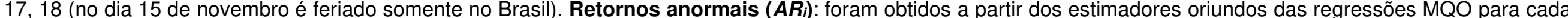

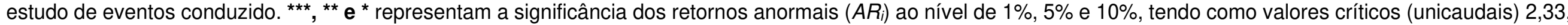

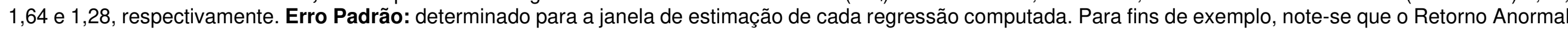

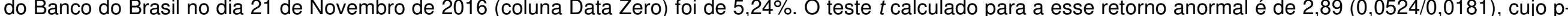

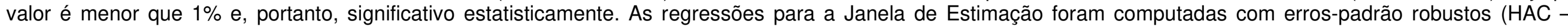

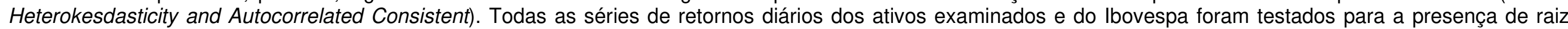
unitária, sendo rejeitada hipótese nula de presença de raiz unitária (ADF test). 
Evidencia-se na Tabela 2 que, embora com níveis de significância de $10 \%$, as ações do Banco Santander (ON e PN) apresentaram reações positivas 1 dia antes do evento divulgado pelo Banco do Brasil. No entanto, a Tabela 2 também mostra que Retornos Anormais negativos e significativos foram observados dias após o evento em estudo (3 e 4 dias após o evento), fato que não ocorreu nem com a ação do Banco do Brasil (BBAS) e nem com seu ADR (BDORY). Essas evidências sugerem que a geração de retornos anormais positivos e significativos esteve concentrada nos ativos deste banco.

Para os ativos do BB Seguridade negociados no Brasil (BBSE) não há resultados significativos em nenhum dos dias da Janela de Eventos indicando que, ao contrário do que analistas esperavam, não houve transmissão negativa do anúncio do plano de Banco do Brasil para as ações do BB seguridade. Uma explicação plausível para essa não reação foi o comunicado feito pelo próprio Banco do Brasil (Em $22 / 11 / 2016$ ) informando que as medidas anunciadas sobre a redução no número de agências equivaleriam a somente $2,5 \%$ do total das unidades de negócios que ofertam produtos de seguros e, portanto, não gerariam restrições na oferta de serviços do BB Seguridade. No que diz respeito aos ativos negociados em Mercado de Balcão nos Estados Unidos (BBSEY), embora não existam evidências de Retornos Anormais significativos na Data Zero, há alternância de retornos positivos e negativos antes (18/11/2016) e após (24 e 25/11/2016) sugerindo uma compensação de retornos ao redor da data do evento em estudo. Indícios sobre a persistência dos Retornos Anormais nas datas circunscritas ao dia 21 de novembro de 2016 poderão ser observados na etapa de Testes de Hipóteses ligados aos Retornos Anormais acumulados apresentados na Tabela 3 a seguir.

Tabela 3 - Resultados dos Retornos Anormais Acumulados (CARi)

\begin{tabular}{|c|c|c|c|c|c|}
\hline Seq. & $\frac{5 \text { dias antes até }}{\text { a DZ }}$ & $\frac{4 \text { dias antes até }}{\text { a DZ }}$ & $\frac{3 \text { dias antes até }}{\text { a DZ }}$ & $\frac{2 \text { dias antes até }}{\text { a DZ }}$ & $\frac{1 \text { dia antes até }}{\text { a DZ }}$ \\
\hline BBDC4 & $1,6 \%$ & $-2,2 \%$ ** & $-2,0 \%$ ** & $-1,5 \%^{*}$ & $-0,1 \%$ \\
\hline BBDC3 & $-1,1 \%$ & $-1,2 \%$ & $0,0 \%$ & $-0,2 \%$ & $-0,1 \%$ \\
\hline ITUB4 & $1,7 \%$ & $-0,6 \%$ & $0,9 \%$ & $-1,9 \%$ ** & $-0,6 \%$ \\
\hline ITUB3 & $0,9 \%$ & $-0,5 \%$ & $1,5 \%$ & $-1,0 \%$ & $0,2 \%$ \\
\hline ABCB4 & $-1,0 \%$ & $0,5 \%$ & $0,2 \%$ & $-0,7 \%$ & $1,2 \%$ \\
\hline BPAN4 & $1,5 \%$ & $-0,2 \%$ & $0,1 \%$ & $0,1 \%$ & $-0,8 \%$ \\
\hline PINE4 & $-0,2 \%$ & $0,6 \%$ & $-0,2 \%$ & $-0,1 \%$ & $-1,7 \%$ \\
\hline BBTG11 & $9,2 \%$ *** & $5,6 \%$ *** & $4,4 \%^{\star \star}$ & $3,1 \%$ & $5,5 \%$ *** \\
\hline BRSR6 & $0,6 \%$ & $-0,8 \%$ & $-1,2 \%$ & $-3,5 \%$ & $-1,4 \%$ \\
\hline BBAS & $10,5 \%^{\star \star \star}$ & $13,5 \% \%^{\star \star \star}$ & $11,8 \%$ \%** & 7,9\%*** & $\underline{7,7 \% * \star \star}$ \\
\hline BDORY & $14,7 \% \%^{\star \star \star}$ & $13,6 \% \%^{\star \star \star}$ & $10,2 \% \%^{\star \star \star}$ & 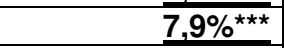 & $11,9 \% \%^{\star \star \star}$ \\
\hline BBSE & $0,5 \%$ & $-0,2 \%$ & $0,5 \%$ & $-1,2 \%$ & $-1,1 \%$ \\
\hline BBSEY & $0,9 \%$ & $3,3 \%$ & $0,6 \%$ & $0,0 \%$ & $3,3 \%$ \\
\hline SANB3 & $16,0 \% \%^{\star \star *}$ & $18,9 \%$ *** & $12,6 \%$ *** & $5,8 \%$ & $9,9 \%$ *** \\
\hline SANB4 & $2,0 \%$ & $1,4 \%$ & $-2,5 \%$ & $5,1 \%$ & $5,0 \%$ \\
\hline
\end{tabular}

Fonte: elaborado pelos autores (2018)

Mostra-se na Tabela 3 que os Retornos Anormais Acumulados (CARi) para os ativos do Banco do Brasil (BBAS e BDORY) são os únicos da análise a se manterem significativos tanto para a acumulação mais longa ( 5 dias antes do anúncio até o dia 21 de novembro) quando para a janela mais curta (1 dia antes até o anúncio até o dia 21 de novembro). Nessa direção, pode-se rejeitar a Hipótese Nula de que os Retornos Anormais Acumulados para os ativos do Banco do Brasil são negativos ou iguais a zero, reconhecendo a hipótese de que ao longo da Janela de Eventos eles são significativos. Ressalte-se que diversas simulações foram realizadas para acumulação de Retornos Anormais, as quais se mostraram persistentemente positivas (ao nível de $5 \%$ e 1\%). Tais resultados não estão integralmente reportados nesta seção em função de limitações espaço. Além disso, com o objetivo de mostrar os resultados mais conservadores encontrados, decidiu-se mostrar os CARs mais restritivos para fins análise de dados da pesquisa.

Embora a Tabela 3 exiba que Retornos Anormais Acumulados positivos e significativos não foram observados na maioria dos ativos analisados, o que corrobora a ideia de que o anúncio do plano do Banco do Brasil conduziu conteúdo informacional ao mercado acionário, os resultados constatados para o $C A R$ do Banco Santander e Banco BTG Pactual não podem ser ignorados. Nessa direção, há duas reflexões que podem explicar essa reação anormal nos dois Bancos (Tabelas 2 e 3). A primeira é que também no dia 21 de Novembro foi noticiado que tanto o Santander quanto do Banco do Brasil estiveram diretamente envolvidos em uma negociação em que a holding da CEMIG (Companhia Energética de Minas Gerais) aumentava sua participação na empresa Parati Participações em Ativos de Energia Elétrica em R \$ 447,7 milhões (MAIA, 2016), o que pode ter impulsionado o preço das ações do Santander nesse intervalo. Outra possível explicação é que um ou mais investidores proprietários de ações do Santander e BTG Pactual, mas que também são proprietários de ações do Banco do Brasil, podem ter obtido informações antecipadas sobre a consistência do plano de Reorganização Institucional a ser conduzido pelo Banco do Brasil e alterado posições em suas carteiras de investimento direcionando para cima o preço das ações do próprio Santander. Esse segundo argumento se sustenta na forte semelhança entre os retornos anormais simples e acumulados do Banco do Brasil e do Santander para a Janela de Eventos estudada.

$\mathrm{Na}$ direção de auxiliar na interpretação das implicações dos sinais positivos (e significativos) dos 
retornos anormais constatados nos ativos do Banco do Brasil já mostrados previamente, a Tabela 4 evidencia o desdobramento da capitalização de mercado da instituição financeira no período circunscrito à Janela de Eventos utilizada.

Tabela 4 - Capitalização de mercado do Banco do Brasil em bilhões de reais entre 11 e 28 de novembro de 2016

\begin{tabular}{c|c|c|c|c|c|c|c|c|c|c|c}
\hline & $11 / 11$ & $14 / 11$ & $16 / 11$ & $17 / 11$ & $18 / 11$ & $21 / 11$ & $22 / 11$ & $23 / 11$ & $24 / 11$ & $25 / 11$ & $28 / 11$ \\
\hline $\mathrm{MC}$ & 68,08 & 69,97 & 74,50 & 73,13 & 75,27 & 81,18 & 81,89 & 81,52 & 79,34 & 79,17 & 82,81 \\
\hline
\end{tabular}

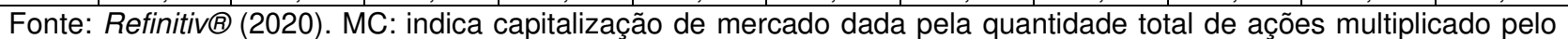
preço da ação no dia. Coleta realizada conforme dados disponíveis na base de dados Refinitiv® especificado pelo datatype MVC (Market Value for Company) em série diária.

Coerente com os resultados já apresentados nas Tabelas 2 e 3, mostra-se na Tabela 4 importante evolução da capitalização de mercado da instituição, sendo possível pelo menos duas considerações. A primeira é que os três retornos anormais positivos mostrados na Tabela 2 dados por $3,96 \%, 2,47 \%$ e 5,24\% e respectivos aos dias 16,18 e 21 de novembro, elevaram o patamar de capitalização de mercado da instituição para acima dos $R \$ 81$ bilhões, sendo que especificamente no dia em que o Plano de Reorganização Institucional foi comunicado ao mercado o salto de capitalização foi de $\mathrm{R} \$ 5,9$ bilhões (diferença entre 81,18 e 75,27).

Além disso, é possível notar que após o dia do evento não houve queda substancial do valor e a janela de eventos foi encerrada com capitalização de mercado de $R \$ 82,81$ bilhões e, portanto, acúmulo de quase $R \$ 14,73$ bilhões (diferença entre 82,81 e 68,08) para o intervalo. A partir dessas verificações, podese argumentar os resultados apontam que os retornos anormais determinados têm materialidade econômica porque evidenciam importante evolução no valor da capitalização de mercado diária do banco, não restrita à análise de sinais e significâncias estatísticas.

Embora o propósito deste estudo esteja ancorado na constatação de condução de conteúdo informacional do anúncio feito pela instituição financeira e, portanto, busca fazer inferências dentro de rigor metodológico compatível e tolerado, o Gráfico 1 também pode amparar, ainda que lateralmente, a compreensão de possíveis efeitos do anúncio sobre o desempenho da instituição em períodos subsequentes a novembro de 2016. O Gráfico 1 tem como objetivo mostrar trimestralmente a evolução da proporção de Capex (Capital Expeditures) sobre o total de ativos e o retorno sobre patrimônio líquido (ROE) entre 2014 e 2019.

Gráfico 1 - Evolução do Capex e ROE do Banco do Brasil de 2014 a 2019

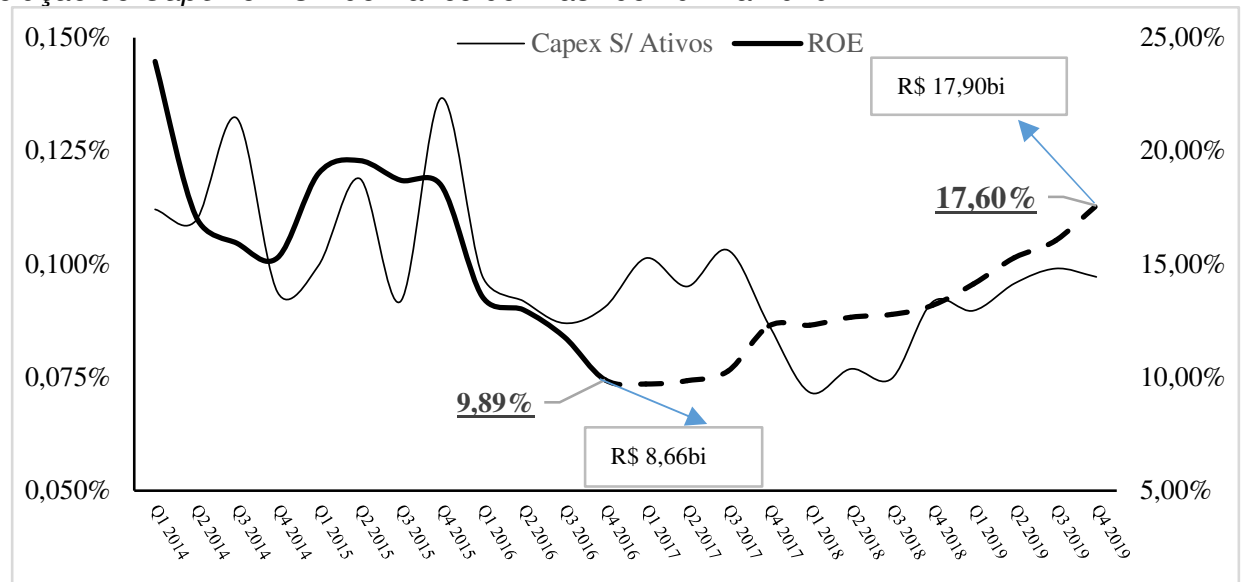

Fonte: Elaborado pelos Autores (2020).

Nota-se no Gráfico 1 que as adições de tangíveis e intangíveis apresentaram discreto incremento em período que coincide com o anúncio do Plano de Reorganização se estendendo até próximo ao final do ano de 2017, com recuo em 2018 e voltando a aumentar a partir do final deste ano até o encerramento de 2019. Esses resultados sugerem que o esforço de redução de mão de obra, redução de estrutura de agências e outras unidades operacionais, não representaram cortes de planos de investimentos que pudessem limitar a infraestrutura operacional da instituição a ponto de limitar seu crescimento. Além disso, é possível observar que essas adições de ativos se mantiveram mesmo no período em que o ROE seguia trajetória de estabilização de queda e reversão para ascendência.

Embora fatores internos e externos possam ter interagido com as medidas que compunham o Plano de Reorganização e redirecionado a instituição para recompor sua rentabilidade, deve-se observar que o ROE imediatamente anterior ao anúncio do Plano (terceiro trimestre de 2016) foi de 9,89\% e lucro líquido do exercício de 2016 em $\mathrm{R} \$ 8,66$ bilhões. Ao final de 2019 , o ROE trimestral divulgado foi de $17,6 \%$ com $\mathrm{R} \$$ 17,90 bilhões de lucro líquido anual e, portanto, mostrando aumento de $77,96 \%$ no ROE na comparação entre 
o terceiro trimestre de 2016 e o último divulgado em 2019 , e aumento de $106,70 \%$ entre os lucros anuais de 2016 e 2019.

Com o objetivo de examinar quão sensível à presença de outliers são os resultados apresentados para os ativos do Banco do Brasil (BBAS e BDORY), a Tabela 5 apresenta os Retornos Anormais $\left(A R_{i}\right)$ recalculados a partir de métodos de estimação robusta.

Tabela 5 - Retornos Anormais $(A R i)$ recalculados com estimadores robustos

\begin{tabular}{|c|c|c|c|c|c|c|c|c|}
\hline \multirow{2}{*}{ Dias } & \multicolumn{4}{|c|}{ Estimador de Desvio Mínimo Absoluto (LAD) } & \multicolumn{4}{|c|}{ Estimador MM } \\
\hline & BBAS3 & BDORY & BBSE & BBSEY & BBAS3 & BDORY & BBSE & BBSEY \\
\hline $5 A$ & $-3,37 \%$ ** & $1,21 \%$ & $0,57 \%$ & $-2,32 \%$ & $-3,31 \%$ ** & $1,20 \%$ & $0,60 \%$ & $-2,3 \%$ \\
\hline $4 \mathrm{~A}$ & $1,79 \%$ & $3,44 \%$ & $-0,67 \%$ & $2,60 \%$ & $1,80 \%$ & $3,41 \%$ & $-0,73 \%$ & $2,6 \%$ \\
\hline $3 \mathrm{~A}$ & $4,13 \%$ ** & $2,38 \%$ & $1,89 \%$ & $0,64 \%$ & $4,13 \%$ ** & $2,38 \%$ & $1,81 \%$ & $0,6 \%$ \\
\hline $2 \mathrm{~A}$ & $-0,01 \%$ & $-4,05 \%$ * & $-0,16 \%$ & $-3,27 \%$ & $0,02 \%$ & $-4,07 \%^{*}$ & $-0,16 \%$ & $-3,3 \%$ \\
\hline $1 \mathrm{~A}$ & $2,49 \%$ * & $4,30 \%{ }^{*}$ & $0,89 \%$ & $4,19 \%$ & $2,51 \%{ }^{*}$ & $4,30 \%^{*}$ & $0,85 \%$ & $4,2 \%$ \\
\hline$\overline{D Z}$ & $5,41 \% \%^{\star \star \star}$ & $7,73 \%$ \%** & $-1,78 \%$ & $-0,88 \%$ & $5,41 \%{ }^{\star \star \star}$ & $7,70 \% \%^{\star \star \star}$ & $-1,86 \%$ & $-0,9 \%$ \\
\hline $1 \mathrm{D}$ & $-0,42 \%$ & $1,63 \%$ & $-0,43 \%$ & $0,50 \%$ & $-0,42 \%$ & $1,62 \%$ & $-0,50 \%$ & $0,5 \%$ \\
\hline $2 \mathrm{D}$ & $-0,55 \%$ & $-2,33 \%$ & $-1,52 \%$ & $-2,84 \%$ & $-0,53 \%$ & $-2,33 \%$ & $-1,56 \%$ & $-2,8 \%$ \\
\hline $3 \mathrm{D}$ & $-1,64 \%$ & $-4,03 \%^{*}$ & $-1,19 \%$ & $-4,93 \%$ & $-1,61 \%$ & $-4,05 \%^{*}$ & $-1,21 \%$ & $-4,9 \%$ \\
\hline $4 \mathrm{D}$ & $-0,56 \%$ & $5,23 \%^{\star \star \star}$ & $-1,10 \%$ & $4,79 \%$ & $-0,54 \%$ & $5,24 \%^{\star \star}$ & $-1,15 \%$ & $4,8 \%$ \\
\hline $5 \mathrm{D}$ & $2,06 \%$ & $-3,17 \%$ & $0,87 \%$ & $-2,51 \%$ & $2,06 \%$ & $-3,18 \%$ & $0,78 \%$ & $-2,5 \%$ \\
\hline
\end{tabular}

Fonte: elaborado pelos autores (2018). Dias são as linhas cujos dias são identificados por A representam dias anteriores e D indicam dias posteriores.

Exibe-se na Tabela 5 que os resultados dos retornos anormais $(A R I)$ para os ativos do Banco do Brasil e BB seguridade não mostraram diferenças quando comparados aos resultados da Tabela 2. No caso específico dos ativos do Banco, os resultados obtidos nos testes $t$ são praticamente idênticos àqueles calculados por meio de MQO. Nesse sentido, os estimadores LAD e MM-Estimador não alteraram os resultados, mantendo-se a rejeição da hipótese nula $\left(\mathrm{H}_{1}: A R_{i}>0\right)$ constada anteriormente. Em relação aos Retornos Anormais do BB Seguridade no Brasil e nos Estados Unidos, em todos foi mantida Hipótese Nula, também coerente com a ideia de ausência de reação para os ativos do BB seguridade.

\section{Considerações Finais}

Esta pesquisa mostrou que o anúncio das medidas denominadas como Reorganização Institucional do Banco do Brasil, embora sua ocorrência já fosse objeto de especulação, trouxe efeitos favoráveis à valoração das ações negociadas pelo Banco do Brasil no Brasil e nos Estados Unidos. Esses efeitos se traduziram em materialidade de conteúdo por meio do Fato Relevante que continha as medidas. $O$ comunicado propagou efeitos no dia do seu anúncio, e exclusivamente para ativos do banco, gerou Retornos Anormais significativos ao nível de $1 \%$ evidenciando que o mercado acionário interpretou o conjunto de medidas como uma surpresa positiva. Intui-se que, embora as medidas já fossem aguardadas, o seu alcance foi elevado o suficiente para que investidores observassem as decisões tomadas como adequadas para recondução da rentabilidade do banco a níveis mais elevados no futuro. Os achados desse estudo indicam ainda que ao longo dos dias seguintes ao evento, os retornos positivos gerados não se reverteram, sugerindo valoração própria do anuncio realizado.

Os resultados desse estudo permitem pelo menos três considerações. A primeira se refere ao fato de que $o$ anúncio não envolveu retrações de investimentos tangíveis e intangíveis, fato que poderia ser um limitador para a expansão futura do banco. O não envolvimento de restrições de gastos de capital foi combinado com uma política de redução de gastos recorrentes de mão de obra na casa de $R \$ 2$ bilhões anuais e intensos cortes departamentais que deixam mais de 9.000 funcionários a disposição para realocação. Tomadas em conjunto, tais medidas podem ter sido interpretadas como uma sinalização de que no futuro não só a rentabilidade do banco seria recomposta como também o payout de dividendos seria aumentado, colocando o investidor posição mais favorável.

A segunda é que essas medidas foram acompanhadas por anúncios de redirecionamento de receitas por meio da utilização mais intensa de canais digitais, o que afetaria positivamente não só a receita do banco, mas a eficiência da instituição. A terceira é que nenhum fragmento do anúncio levou a interpretação de que o banco poderia precisar de aportes do Tesouro Nacional para tomar medidas que resguardassem sua capacidade de atuação. Ao contrário, o banco pode ter sinalizado sobre sua capacidade financeira em promover mudanças profundas na sua estrutura de funcionamento sem ajuda do Governo Federal, seu maior acionista.

O presente estudo também mostrou que os efeitos significativos estiveram concentrados nos retornos anormais dos ativos do Banco do Brasil no dia 21 de novembro. Isso significa que esses efeitos não se trataram de uma coincidência ou ocorrência generalizada tendo em vista terem sido comparados com resultados de outros bancos, conferindo assim consistência aos achados. Adicionalmente, esse artigo utilizou estimadores que podem ser considerados resilientes à presença de outliers, o que pode auxiliar na verificação 
de robustez ou fragilidade de testes de significância na condução de estudos de eventos em estudos futuros.

Em termos de contribuição para a literatura na área de contabilidade e finanças, o conjunto de resultados mostrados nesta pesquisa contribui para a discussão da reação do mercado acionário à circunstâncias envolvendo a Hipóteses de Dificuldade Financeiras e a Hipótese de Benefícios Potenciais, o que na prática representa um refinamento em termos de interpretação de resultados além da Hipótese de Mercados Eficientes.

Diferente de estudos internacionais realizados em países que têm mercados de capitais mais desenvolvidos e com número superior de empresas, este estudo analisou somente o caso de um anúncio, embora seja de um banco com mais de $R \$ 1$ trilhão em ativos anuais. Apesar do estudo não se limitar aos ativos do Banco do Brasil, trata-se de um estudo único o que impõe limitações no que concerne a comparação de resultados.

O trajeto percorrido para desenvolvimento desta pesquisa permitiu reflexões que podem ser apresentadas como indicações de pesquisas futuras. Como típico estudo sobre mercados financeiro e de capital, esta pesquisa apresenta uma perspectiva que contempla predominantemente a lente de usuários externos da contabilidade. No entanto, os reflexos do Plano de Reestruturação Institucional do Banco do Brasil podem ser compreendidos pela lente do usuário interno e, portanto, por meio de proposições e hipóteses advindas da Contabilidade Gerencial. Assim, o olhar "porta para dentro" poderá ampliar a compreensão do significado deste plano na busca da recomposição da rentabilidade da instituição.

O contexto de implementação do Plano de Reestruturação ocorreu no ano de impeachment do chefe do poder executivo e com o envolvimento do de um dos profissionais que ocuparam a posição de Presidente do Conselho de Administração do Banco do Brasil em crimes de corrupção. Sabe-se que é por meio da Casa Civil do Governo Federal que ocorrem as escolhas de executivos que deverão ocupar posições de primeiro escalão em companhias estatais. Nesse sentido, uma indicação para estudos futuros no campo da Finanças Públicas é examinar como possíveis mudanças de gestores públicos de companhias estatais pode ter impactado o desempenho dessas companhias a partir daquele momento até os períodos atuais.

\section{Referências}

ABOWD, John M.; MILKOVICH, George T.; HANNON, John M. The effects of human resource management decisions on shareholder value. ILR Review, v. 43, n. 3, p. 203-S-236-S, 1990.

https://doi.org/10.1177/ 001979399004300313

ALVARENGA, Danilo. Programas de cortes em estatais têm adesão de mais de 37 mil funcionários em 2 anos. G1 Globo.com. Recuperado de https://g1.globo.com/economia/noticia/programas-de-cortes-emestatais-tem-adesao-de-mais-de-37-mil-funcionarios-em-2-anos.ghtml. Acesso em 09/01/2017.

BALLESTA, Marta; LIVNAT, Joshua; SINHA, Nishi. Corporate reorganizations: Changes in the intensity of labor and capital expenditures. Journal of Business Finance \& Accounting, v. 26, n. 9-10, p. 1205-1238, 1999. https://doi.org/10.1111/1468-5957.00294

BANCO DO BRASIL. Com foco no atendimento digital, BB anuncia reorganização institucional e plano de aposentadoria incentivada. Recuperado de http://www.bb.com.br/pbb/pagina-inicial/imprensa/n/53839/comfoco-no-atendimento-digital-bb-anuncia-reorganizacao-institucional-e-plano-de-incentivo-a-aposentadoria\#/. Acesso em 21/11/2016.

BENNINGA, Simon. Financial modeling, MIT: MIT Press Books, 2008.

BLACKWELL, David W.; MARR, M. Wayne; SPIVEY, Michael F. Plant-closing decisions and the market value of the firm. Journal of Financial Economics, v. 26, n. 2, p. 277-288, 1990.

https://doi.org/10.1111/10.1016/j.jpe.2015.06.029

BLOOMBERG. Bloomberg Terminal. Base de Dados. Curitiba: Universidade Federal do Paraná, Recuperado 16 maio, 2020.

BROOKMAN, Jeffrey T.; CHANG, Saeyoung; RENNIE, Craig G. CEO cash and stock-based compensation changes, layoff decisions, and shareholder value. Financial Review, v. 42, n. 1, p. 99-119, 2007. https://doi.org/10.1111/j.1540-6288.2007.00163

CAGLE, Julie AB; SEN, Amit; WEBB, Shelly. The valuation effect of financial institution layoff announcements: the role of corporate governance. J Bus Econ Perspect, v. 30, p. 13-23, 2004.

CAGLE, Julie AB; SEN, Amit; PAWLUKIEWICZ, James E. Inter-industry differences in layoff announcement effects for financial institutions. Journal of Economics and Finance, v. 33, n. 1, p. 100-110, 2009. 
https://doi.org/10.1007/s12197-008-9062-2

CHADWELL, Paul.; FILBECK, Greg. The Share Price Effects of Layoff Announcements. J Bus Econ Perspect, v. 20, n. 10, 1994.

CHADWELL, Paul.; MULLINEAUX, D. Bank holding company restructuring strategies: an examination of the share price effects of selloffs and layoffs. New York Economic Review, 3-12, 1995. https://doi.org/10.1111/j.1540-6288.1993.tb01355

CHALOS, Peter; CHEN, Charles JP. Employee downsizing strategies: Market reaction and post announcement financial performance. Journal of Business Finance \& Accounting, v. 29, n. 5-6, p. 847870, 2002. https://doi.org/10.1111/1468-5957.00453

CHEN, Peter; VIKAS, Mehrotra; RANJINI, Sivakumar; WAYNE, W. Yu. Layoffs, shareholders' wealth, and corporate performance. Journal of Empirical Finance, v. 8, n. 2, p. 171-199, 2001.

https://doi.org/10.1016/S0927-5398

DIEESE. Desempenho dos Bancos 2016. Abril, 2017. Disponível em <https://www.dieese.org.br/desempenhodosbancos/2016/desemprenhoDosBancos2016.html>. Acesso em: 12 de Nov. 2017

CARRIJO, Débora Couto; NAVARRO, Vera Lucia. LER e planos de demissão voluntária: trajetórias de dor e sofrimento entre bancários. Cadernos de Psicologia Social do Trabalho, v. 12, n. 2, p. 157-171, 2009.

ELAYAN, Fayez A.; SWALES, George S.; MARIS, Brian A.; SCOTT, James R. Market reactions, characteristics, and the effectiveness of corporate layoffs. Journal of Business Finance \& Accounting, v. 25, n. 3-4, p. 329-351, 1998. https://doi.org/10.1111/1468-5957.00190

FARBER, Henry S.; HALLOCK, Kevin F. The changing relationship between job loss announcements and stock prices: 1970-1999. Labour Economics, v. 16, n. 1, p. 1-11, 2009.

https://EconPapers.repec.org/RePEc:eee:labeco:v:16:y:2009:i:1:p:1-11

FEBRABAN. Mobile banking se torna o preferido dos brasileiros para transações bancárias, revela FEBRABAN. Disponível em <https://portal.febraban.org.br/noticia/3083/pt-br/>. Acesso em 29/05/2017.

FILBECK, Greg; WEBB, Shelly E. Information asymmetries, managerial ownership, and the impact of layoff announcements on shareholder wealth. Quarterly Journal of Business and Economics, p. 31-47, 2001. https://doi.org/10.1111/10.2307/40473327

GOMBOLA, Michael J.; TSETSEKOS, George P. Plant closings for financially weak and financially strong firms. Quarterly Journal of Business and Economics, p. 69-83, 1992.

GUNDERSON, Morley; VERMA, Anil; VERMA, Savita. Impact of layoff announcements on the market value of the firm. Relations Industrielles/Industrial Relations, v. 52, n. 2, p. 364-381, 1997.

https://doi.org/10.7202/051170ar

HAHN, Tewhan; REYES, Mario G. On the estimation of stock-market reaction to corporate layoff announcements. Review of Financial Economics, v. 13, n. 4, p. 357-370, 2004. .

https://doi.org/10.1111/10.1016/j.rfe.2003.12.004

HILLIER, David; MARSHALL, Andrew; McCOLGAN, Patrick. Employee layoffs, shareholder wealth and firm performance: Evidence from the UK. Journal of Business Finance \& Accounting, v. 34, n. 3-4, p. 467494, 2007. http://dx.doi.org/10.1111/j.1468-5957.2007.02042

IPEA. ipeadata. Disponível em < http://www.ipeadata.gov.br/exibeserie>. Acesso em: 25 de Jan. 2018

IQBAL, Zahid; SHETTY, Shekar. Layoffs, stock price, and financial condition of the firm. Journal of Applied Business Research, v. 11, n. 2, p. 67, 1995. https://doi.org/10.19030/jabr.v11i2.5876

JELMAYER, Richard. Banco do Brasil to Close Branches, Concentrate on Digital Channels. The Wall Street Journal. Recuperado de https://www.wsj.com/articles/banco-do-brasil-to-close-branches-concentrate-ondigital-channels-1479731444. Acesso em 21/11/2016 
KUNERT, Stephan; SCHIERECK, Dirk; WELKOBORSKY, Christopher. Stock market reactions to layoff announcements-analysis of the renewable energy sector. International Journal of Energy Sector Management, v. 11, n. 2, p. 311-328, 2017. https://doi.org/10.1108/IJESM-02-2016-0004

KRISHNAN, Hema A.; PARK, Daewoo. The impact of work force reduction on subsequent performance in major mergers and acquisitions: an exploratory study. Journal of Business Research, v. 55, n. 4, p. 285292, 2002. https://doi.org/10.1016 / S0148-2963 (00) 00166-1

LIN, Ji-Chai; ROZEFF, Michael S. Capital market behavior and operational announcements of layoffs, operation closings, and pay cuts. Review of Quantitative Finance and Accounting, v. 3, n. 1, p. 29-45, 1993.

LEE, Peggy. A comparative analysis of layoff announcements and stock price reactions in the United States and Japan. Strategic Management Journal, v. 18, n. 11, p. 879-894, 1997. https://doi.org/10.1002/(SICl)1097-0266(199712)18:11<879::AID-SMJ929>3.0.CO;2-V

MADURA, Jeff; AKHIGBE, Aigbe; BARTUNEK, Kenneth S. Intra-industry effects of bank layoff announcements. Review of Financial Economics, v. 4, n. 2, p. 187-195, 1995.

http://dx.doi.org/10.2139/ssrn.3242362

MENTZER, Marc S. Corporate downsizing and profitability in Canada. Canadian Journal of Administrative Sciences/Revue Canadienne des Sciences de l'Administration, v. 13, n. 3, p. 237-250, 1996. https://doi.org/10.1111/ j.1936-4490

NIXON, Robert D.; HITT, Michael A.; LEE, Ho-Uk; JEONG, Eui. Market reactions to announcements of corporate downsizing actions and implementation strategies. Strategic Management Journal, v. 25, n. 11, p. 1121-1129, 2004.

RIZÉRIO, L. "Enxugamento" do BB é celebrado por analistas, mas deve afetar uma queridinha da Bolsa. Infomoney. 2016. Recuperado de http://www.infomoney.com.br/bancodobrasil/noticia/5854010/enxugamento-celebrado-por-analistas-masdeve-afetar-uma-queridinha-bolsa. Acesso em 29/05/2020

SEGNINI, Liliana Rolfsen Petrilli. Reestruturação nos bancos no Brasil: desemprego, subcontratação e intensificação do trabalho. Educação \& Sociedade, v. 20, n. 67, p. 183-209, 1999.

SILVA, Fabiana Lima. As mudanças no padrão de gestão do Banco do Brasil: uma análise crítica de seus fundamentos. Planejamento e Políticas Públicas, v.1, n. 1, p. 35-66, 2010.

SILVA, Eduardo Pinto. Programa de demissão voluntária em uma instituição bancária: da gestão da adesão ao programa às complexas perdas psicossociais. Revista Psicologia: Organizações e Trabalho, v. 2, n. 2, p. 143-173, 2002.

SOROKINA, Nonna; BOOTH, David E.; THORNTON JR, John H. Robust Methods in Event Studies: Empirical Evidence and Theoretical Implications. Journal of Data Science, v. 11, 2013. https://doi.org/10.1111/10.2139/ssrn.1928942

TEMÓTEO A.; NUNES V. Banco do Brasil aposenta 9,4 mil e suspende concursos públicos. Correio Braziliense. 2016. Recuperado de http://www.correiobraziliense.com.br/app/noticia/economia/2016/12/12/internas_economia,560909/bancodo-brasil-aposenta-9-4-mil-e-suspende-concursos-publicos.shtml

URSEL, Nancy; ARMSTRONG-STASSEN, Marjorie. The impact of layoff announcements on shareholders. Relations Industrielles/Industrial Relations, v. 50, n. 3, p. 636-649, 1995. https://doi.org/10.7202/051038ar

VELÁSQUEZ, Santiago; KANNIAINEN, Juho; MÄKINEN, Saku; VALLI, Jaakko. Layoff announcements and intra-day market reactions. Review of Managerial Science, v. 12, n. 1, p. 203-228, 2018. https://doi.org/10.1111/10.1007/s11846-016-0219-7

WAYHAN, Victor B.; WERNER, Steve. The impact of workforce reductions on financial performance: A longitudinal perspective. Journal of Management, v. 26, n. 2, p. 341-363, 2000.

https://doi.org/10.1111/10.1177/014920630002600208 
WERTHEIM, Paul; ROBINSON, Michael A. Market reactions to company layoffs: Evidence on the financial distress versus potential benefit hypothesis and the effect of predisclosure information. Journal of Applied Business Research, v. 20, n. 1, p. 51-62, 2004.

WOOLDRIDGE, Jeffrey M. Introductory econometrics: A modern approach. Nelson Education, 2015.

WORRELL, Dan L.; DAVIDSON III, Wallace N.; SHARMA, Varinder M. Layoff announcements and stockholder wealth. Academy of Management Journal, v. 34, n. 3, p. 662-678, 1991.

https://doi.org/10.1111/10.2307 256404

\section{NOTAS}

\section{AGRADECIMENTOS}

Não se aplica.

\section{CONTRIBUIÇÃO DE AUTORIA}

Concepção e elaboração do manuscrito: C.M.E., Barros; S.U., Azevedo.

Coleta de dados: C.M.E Barros, A. K. Negrão

Análise de dados: C.M.E Barros

Discussão dos resultados: C.M.E Barros S.U., Azevedo e J. D Teodoro.

Revisão e aprovação: C.M.E Barros, S.U., Azevedo e J. D Teodoro.

\section{CONJUNTO DE DADOS DE PESQUISA}

O conjunto de dados que dá suporte aos resultados deste estudo não está disponível publicamente.

\section{FINANCIAMENTO}

Não se aplica.

\section{CONSENTIMENTO DE USO DE IMAGEM}

Não se aplica.

\section{APROVAÇÃO DE COMITÊ DE ÉTICA EM PESQUISA}

Não se aplica.

\section{CONFLITO DE INTERESSES}

Não se aplica.

\section{LICENÇA DE USO}

Os Direitos Autorais para artigos publicados neste periódico são do autor, com direitos de primeira publicação para a Revista. Em virtude de aparecerem nesta Revista de acesso público, os artigos são de uso gratuito, com atribuições próprias, em aplicações educacionais, de exercício profissional e para gestão pública. A Revista adotou a licença Creative Commons Atribuição 4.0 Internacional - CC BY NC ND. Esta licença permite acessar, baixar (download), copiar, imprimir, compartilhar, reutilizar e distribuir os artigos desde que com a citação da fonte, atribuindo os devidos créditos de autoria. Nesses casos, nenhuma permissão é necessária por parte dos autores ou dos editores. Autores têm autorização para assumir contratos adicionais separadamente, para distribuição não-exclusiva da versão do trabalho publicada nesta revista (ex.: publicar em repositório institucional ou um capítulo de livro).

\section{PUBLISHER}

Universidade Federal de Santa Catarina. Curso de Ciências Contábeis e Programa de Pós-graduação em Contabilidade. Publicação no Portal de Periódicos UFSC. As ideias expressadas neste artigo são de responsabilidade de seus autores, não representando, necessariamente, a opinião dos editores ou da universidade.

\section{EDITORES}

Carlos Eduardo Facin Lavarda e Suliani Rover

\section{HISTÓRICO}

Recebido em: 02/12/2018 - Revisado por pares em: 28/04/2020 - Reformulado em: 01/05/2020 Recomendado para publicação em: 02/05/2020 - Publicado em: 30/05/2020

Uma versão preprint do artigo foi apresentada no congresso USP de Contabilidade e Controladoria, 2018. 